\title{
Usos do entretenimento como estratégia de visibilidade política na página da prefeitura de Curitiba no Facebook
}

\section{Uses of entertainment as a political visibility strategy on Curitiba's city hall Facebook page}

Luís Mauro Sá Martino ${ }^{1}$ e Tayra Carolina Aleixo² 


\section{Resumo}

Este texto delineia algumas condições de visibilidade midiática a partir do uso do entretenimento por agentes da esfera política, tomando como estudo de caso a página da prefeitura de Curitiba-PR, no site de rede social Facebook. A pesquisa, realizada a partir da análise das postagens, bem como uma entrevista realizada junto ao gestor de comunicação da prefeitura curitibana, articulada com levantamento bibliográfico, sugere que o uso do entretenimento parece contribuir para um aumento da interlocução entre prefeitura e munícipes via internet, bem como a projeção de visibilidade do órgão.

\section{Palavras-chave}

Comunicação, política, entretenimento, teoria da comunicação, processos midiáticos.

\section{Abstract}

The article outlines some aspects of the relationship between entertainment and politics as it has been shown by Curitiba's fan page on Facebook. Empirical data has been taken from the posts and interaction on the page, combined with an interview with the page's publisher and bibliographical research. Results suggest that entertainment on social media increases the communication between citizens and prefecture as well as the promotion of political actions.

\section{Keywords}

Communication, politics, entertainment, communication theory, social media processes. 
A esfera política tende a ser pensada como um espaço de racionalidade. A troca conversacional, bem como o sistema de tomada de decisões, parece necessariamente se pautar na troca de argumentos racionais com vistas ao entendimento. Nessa tradição, que contempla todo um debate envolvendo pensadores como Habermas (1997, 2004) e Rawls (2004), o espaço da política estaria separado dos afetos - e, nesse aspecto, estaria nas antípodas do entretenimento.

Entretanto, a vida pessoal e o lado emocional não podem ser dissociados da rotina profissional ou cidadã do ser humano, como apontou Muniz Sodré (GROHMANN, 2015), ao indicar que sempre haverá motivações pessoais por trás de questões políticas e profissionais. Se o núcleo de uma política deliberativa se concentrava nos aspectos de um "uso público da razão", a contrapartida de várias autoras e autores está centrada no laço indissociável entre os argumentos racionais e os vínculos afetivos. Essas estratégias são chamadas de "estratégias sensíveis" na obra de Muniz Sodré (2006) e consistem em reconhecer o "sentir" como potencial formador de opinião e tomador de decisão por parte do eleitorado.

Em trabalho anterior, Aleixo $(2014,2016)$ sugere que alguns atores da esfera política vêm utilizando conteúdo de cunho pessoal, às vezes próximo do entretenimento, para ganhar visibilidade tanto em suas campanhas tradicionais como também na rotina de postagens on-line - como, por exemplo, uma candidata ou parlamentar que destaca a identidade materna para atingir determinada parcela do eleitorado feminino.

A racionalidade da decisão político-eleitoral, no caso, parece ser acompanhada diretamente por elementos afetivos constituídos em uma argumentação que não se resume à enumeração de propostas, mas a um elemento dramatúrgico vinculado ao componente político (FRIDJA; KUIPERS; TERSCHURE, 1989; CARLSON; HATFIELD, 1991; VAN ZOONEN, 2004; GROHMANN, 2015).

Em outras palavras, parece existir uma estreita relação entre emoção e comportamento político, despertando tanto gestos de identificação quanto de oposição (FUNG; NAMKOONG; SCHUEFELE, 2012). Dentre as diversas tentativas 
de interpretar a face afetiva da política e suas relações com o entretenimento, Babcock e Whitehouse (2005) destacam a visibilidade midiática como fator de sucesso para o político, enquanto Young e Soroka (2012) mostram o alcance de frases e palavras-chave de alto conteúdo afetivo, além, como mostram Wojdynski e Riffe (2011), da tematização dramatúrgico-midiática da vida pessoal do político.

As imbricações entre afeto e política tornam-se particularmente relevantes quando se pensa que, articulada com a esfera do entretenimento midiático, a política endereça suas mensagens preferencialmente às referências afetivas de potenciais eleitores e eleitoras (WEBER, 2000; GOMES, 2005; GONZÁLEZBAILÓN; BANCHS; KALTENBRUNNER, 2012).

O presente artigo interpreta o uso do entretenimento e do afeto na distribuição de informações on-line da prefeitura de Curitiba como um possível fenômeno que, ao mesmo tempo, aumente sua visibilidade midiática a partir dos vínculos afetivos decorrentes do uso do entretenimento e da cultura da mídia.

Para tanto, a pesquisa buscou notícias sobre a fan page da prefeitura curitibana em grandes portais de notícias na internet e também realizou uma entrevista semiestruturada via Skype com o gestor Marcos Giovanella, responsável pela implantação da estratégia de comunicação da página que ancora suas postagens no tom pessoal e de entretenimento da conversação on-line.

O artigo explora a possibilidade de estudo sobre afeto e política acerca do tom pessoal na linguagem que atores políticos utilizam para expor conteúdos de utilidade pública na rede. O modo como digitam as mensagens e compõem as imagens postadas carregam um tom de proximidade com os followers (usuários que curtiram a fan page), sugerindo um contato mais próximo com as pessoas.

\section{Entretenimento e empatia como estratégia de engajamento político}

As relações entre entretenimento e política vêm sendo estudadas por um número crescente de pesquisadores, tanto nos estudos políticos quanto na 
área de comunicação. Se, à primeira vista, os dois elementos poderiam ser considerados antípodas, na medida em que a política lida com instâncias "sérias" da vida cotidiana e o entretenimento se afirma como um momento de "descanso", é possível, empiricamente, observar cruzamentos e intersecções que desafiam essa dicotomia.

Vale recordar que algumas das séries norte-americanas de maior sucesso na década de 2010, como Game of Thrones e House of Cards, trabalham diretamente com questões políticas em suas narrativas - e o número de exemplos a citar tenderia substancialmente a mais: alguém poderia mencionar as peças de Sófocles como precursor remoto, passando por Shakespeare e pelo cinema até chegar nos modernos equipamentos de TV sob demanda.

A política, envolvida na lógica midiática, se aproxima das linguagens e estilos do entretenimento. Diversas autoras e autores assinalam esse contato, ressaltando, no entanto, que não é possível derivar daí nem uma relação causal nem redutora, seja no sentido de supor uma "influência" unidirecional do entretenimento na política, seja em termos de resumir as atividades do campo político aos acontecimentos e demandas da esfera midiática.

Não se trata, evidentemente, de sugerir qualquer diluição de fronteiras entre as práticas: como recorda Meyer (2002), se a "lógica da mídia" está mais e mais interseccionada com a "lógica da política", a ponto de o autor ver uma "colonização" da última pela primeira, por outro lado ele mesmo não deixa de assinalar que, fora do aspecto propriamente midiático, a "lógica da política" continua existindo no espaço dos gabinetes. No entanto, como indica o autor, seria muito difícil negar que alguns aspectos das práticas políticas tenham sido de alguma maneira adaptados às demandas do espetáculo midiático, sem as quais não há pretensão de alcance de uma visibilidade pública fundamental para a política - estudos de Weber (2001, 2006), e Gomes (2005), por exemplo, sugerem esse fenômeno.

Ao mesmo tempo, esse contato com a "lógica da mídia", indicada por Meyer (2002), não se restringe à adoção de estratégias de comunicação por partidos e 
governos, como a contratação de agências de comunicação para divulgar suas atividades ou mesmo a criação de veículos próprios. O espectro coberto por essas relações parece ser bastante amplo, contemplando, em particular, a esfera do entretenimento.

Em uma cultura midiática na qual os conteúdos de entretenimento ocupam parte considerável das produções, algumas transformações das formas de visibilidade pública da política dificilmente escapariam à adoção, maior ou menor, desses modelos. Na medida em que a lógica da cultura da mídia pauta-se em boa medida pela ideia de entretenimento - da qual o próprio jornalismo não escapa, como sugerem Aguiar (2008), Dejavite (2006) ou Coutinho (2012) -, a comunicação das ações do campo político parece seguir, de alguma forma, esse modelo.

Street $(1997,2001)$ sugere que a intersecção com a mídia de certa maneira alterou o sentido de algumas das práticas específicas do campo político, que se voltam para a conquista de espaços de visibilidade utilizando linguagens próprias do entretenimento. A política mediada nos espaços da comunicação ganha "novos estilos" mencionados por Corner e Pels (2004) ou Washbourne (2010), ao passo que Van Zoonen (2004) leva a perspectiva mais longe, falando de uma "dramatização da política" na mídia, utilizando elementos próximos das linguagens do entretenimento, como a teledramaturgia e os reality shows, no sentido de se aproximar de um público altamente familiarizado com esses modelos.

A noção de "política" ganha contornos mais elásticos, pensada não mais apenas em termos institucionais de governos e partidos, mas também como configuração das relações de poder em uma sociedade - em certo vocabulário acadêmico, isso se traduz nas noções, por exemplo, de "políticas de identidade" ou "políticas sociais". Ao mesmo tempo, a ideia de "humor" justapõe-se à noção contemporânea de "entretenimento" que, sem ser necessariamente humorístico ou jocoso, divide com a noção de humor a perspectiva de algo menos denso, dentro de uma perspectiva que os opõe à seriedade esperada 
das relações cotidianas. O entretenimento, assim como o humor, tende a ser colocado socialmente em oposição aos momentos ditos "sérios" do cotidiano, constituindo uma esfera de escape para as vicissitudes e demandas da vida social (DYER, 1997).

Se a presença de elementos do entretenimento e, em particular, do humor, nas expressões comunicacionais do campo político, deriva de um referencial que se imagina presente no conjunto da sociedade, a intersecção com elementos da chamada "cultura pop" não é uma surpresa. A tese da "dramatização da política", no caso, ganha força redobrada quando se observa que não apenas a exposição jornalística da política - e, portanto, mediada por procedimentos e linguagens inerentes ao campo do jornalismo - se reveste desse caráter, mas, sobretudo, quando mensagens oriundas do próprio campo político se articulam dessa maneira. É o caso, por exemplo, da comunicação de instâncias políticas e administrativas que se valem do entretenimento como uma linguagem para expor suas mensagens à população.

Sob a perspectiva afetiva da política, a empatia é um componente essencial para conquistar eleitores. Tal empatia pode ser observada nas novas abordagens lançadas por figuras políticas na internet. No ambiente conectado há a possibilidade de mapear as preferências dos usuários, fornecendo, a partir de cálculos e logaritmos específicos desses sistemas, os dados para a exposição, em um momento seguinte, de conteúdos políticos potencialmente atrativos.

Entretanto, essa forma de classificar os sites tende a expor pontos de vistas hegemônicos, o que vai contra a ideia de que a internet é democrática. Por outro lado, o modelo de recomendação demonstra maiores ganhos do que no ranqueamento geral das notícias e sites (MUTZ; YOUNG, 2011), conforme apontado no tópico anterior.

Essa face recomendativa de conteúdo on-line vai de encontro à ideia de que as pessoas tendem a levar mais em conta opiniões de amigos, colegas e parentes, do que de pessoas que não estão dentro do seu círculo de conhecidos (SODRÉ, 1991). E na internet, o que pode ser entendido como "círculo de 
conhecidos" é potencialmente maior (MUTZ; YOUNG, 2011). Tal perspectiva faz parte do conjunto de argumentos que basearam a decisão da comunicação da prefeitura em adotar esse modo operacional de transmitir mensagens para a população através da interação on-line. Com essa maneira de administrar a fan page, a prefeitura ganhou grande visibilidade on-line. O próximo tópico concentra-se nas possibilidades dessa visibilidade propriamente dita.

\section{Possibilidades a partir do ganho de visibilidade obtido no perfil da "prefs"}

Informações disponibilizadas na internet são pensadas de maneira diferente do que se fossem lançadas na TV ou mídia impressa, e os interessados parecem ter consciência disso (GOMES, 2011). A partir dessa ideia, novas formas de abordar assuntos políticos têm surgido na rede, como é o caso da prefeitura de Curitiba, ao tratar o conteúdo postado no Facebook de maneira inusitada, levando-a a ser reconhecida como a mais acessada pelas internautas em relação aos perfis das demais capitais brasileiras (CASTRO, 2013).

Um dos primeiros elementos de destaque são os "memes" - nome de um tipo específico de imagem de alta difusão na internet, replicadas e transformadas pelos próprios usuários (NUNES, 2004; SHIFMAN, 2013; MARTINO, 2014) - de uma capivara, que se afirmou como uma espécie de mascote da página.

Ao que tudo indica, essa visão corrobora a opção pelo entretenimento como indicador de busca pelo uso de um repertório familiar às cidadãs e cidadãos que acessam a página. Vale notar que esse procedimento não é isento de críticas, sobretudo no sentido de manter os vínculos com a política - assuntos relacionados à própria cidade e à pauta vigente são sempre incorporados nas postagens (CASTRO, 2013).

A entrevista com o gestor sugere a existência de uma preocupação de manutenção da "lógica da política" que sustente a utilização de elementos do entretenimento e da cultura midiática, sob risco de uma imediata perda de legitimidade dessa postura diante de qualquer inépcia percebida no aspecto 
propriamente político do caso. A "interação com o munícipe", reafirmada ao longo da entrevista, parece indicar essa preocupação. Sem uma orientação responsiva, o viés de interagir dialogicamente com essas pessoas seria potencialmente desperdiçado.

A métrica que baliza o sucesso da página é de fato o engajamento, uma vez que a administração volta sua atenção para o número de pessoas que interagem com ela, ao invés do número de seguidores em si (CASTRO, 2013), e convida diretamente o internauta a interagir, como no exemplo a seguir:

Prefeitura Curitiba @Curitiba_PMC - Apr 4

\section{Gostaríamos de enviar esse documento para a@Suzana_Oficial. Parabéns! youtube.com/watch?v=aOaZ52...}

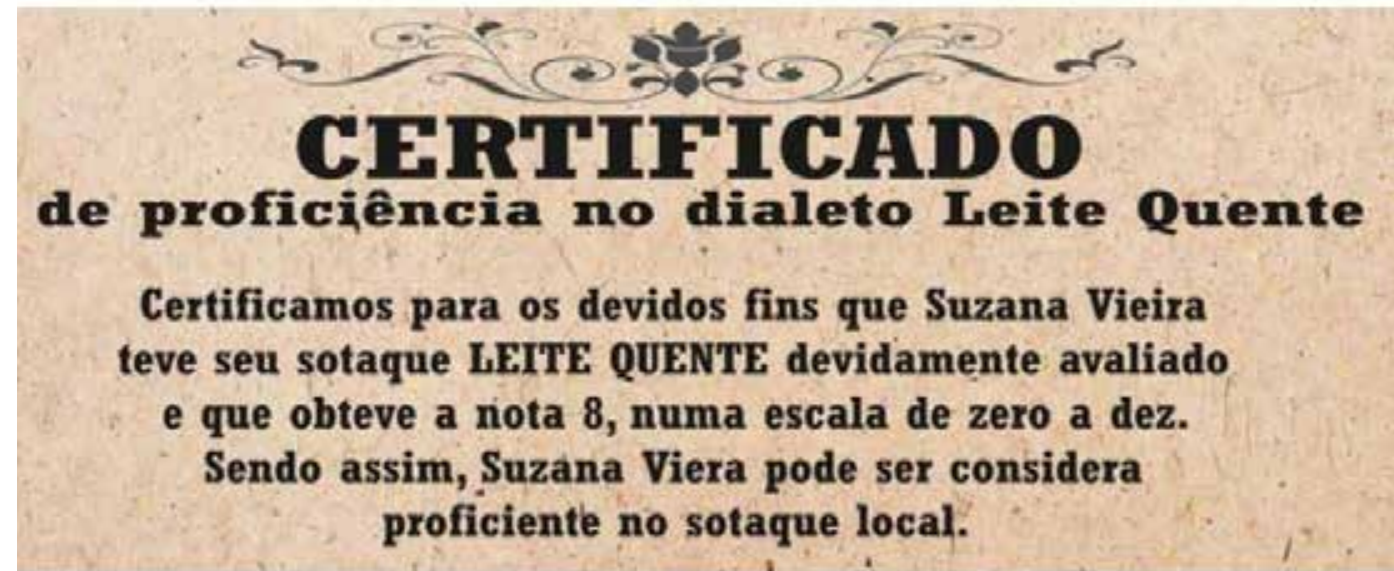

Figura 1: Interação convidativa como estratégia de engajamento segundo face recomendativa da internet

Nesse sentido, enquanto a visibilidade parece ser garantida pela adoção de uma lógica próxima à do entretenimento, a legitimidade se sustenta nas práticas específicas do campo político. A presença de informações de interesse público e ações sociais do governo, bem como o atendimento às demandas da população, reforça esse aspecto. 
A cultura política contemporânea, segundo Wilson Gomes (2005), abriga a crença de que práticas políticas civis não possuem efetividade sobre o poder público, ou seja, não há relação de causa e efeito ao exercer a democracia. Em contrapartida, esse trabalho de relacionamento combinado com atendimento da prefeitura de Curitiba corrobora a ideia de que o debate on-line dá a sensação de que a contribuição de cada participante é valiosa (HYDE-CLARKE, 2013).

Um espaço por excelência para a observação das relações entre política e entretenimento na página da prefeitura de Curitiba talvez sejam os memes elaborados como forma de veiculação dos conteúdos. Se a definição de meme, como observado, está longe de ser um consenso mesmo entre pesquisadores da área, é possível contar com algumas aproximações iniciais.

Sem entrar nos pormenores de sua criação, o conceito de "meme" refere-se, em linhas gerais, a uma ideia compartilhada entre seres humanos a partir de uma transmissão semelhante à dos genes - o parentesco das palavras é intencional, segundo seu criador, o cientista britânico Richard Dawkins (2010). Assim como os genes se multiplicam e se transformam, também os memes seguem essa dinâmica.

Embora precedam a internet e as mídias digitais, os memes encontraram aí um espaço por excelência de multiplicação. Nesse espaço, o nome "meme" é geralmente usado para descrever uma imagem acompanhada de uma pequena frase. Como qualquer mensagem, seu entendimento requer o domínio de inúmeras referências; no entanto, há ao menos duas específicas do meme: a possibilidade de ser reelaborado por qualquer usuário e sua referência constante a elementos da cultura midiática (RECUERO, 2006; SHIFIMAN, 2013; MARTINO, 2014).

Este tópico é dedicado para a modalidade "memes" da conversação online, utilizada também pela prefeitura de Curitiba para atrair os internautas e transmitir mensagens de caráter público. Como apontado na seção anterior, a capivara (meme criado pela equipe de mídias sociais da "prefs") é atualmente um instrumento de geração de receita para o Instituto Pró-Cidadania de Curitiba. 
Em primeiro lugar, o processo de comunicação depende de matrizes interacionais e práticas compartilhadas que influenciam a maneira como a interação avança. Entende-se, nesse caso, a presença de "tais matrizes culturalmente disponíveis no ambiente social (e em constante reelaboração e invenção)" (BRAGA, 2011, p. 5).

A figura da capivara foi criada pelo jornalista Álvaro Borba, hoje responsável pela gestão de mídias sociais da prefeitura. A finalidade do meme da Capivara para a "prefs" era apontar a descontinuidade da linguagem no perfil da instituição, sinalizando a quebra da anterior para dar espaço à nova linguagem que Marcos Giovanella e sua equipe pretendiam implantar em 2013.

Desde sua criação, a capivara já foi apresentada de inúmeras formas na rede, tanto em postagens da própria prefeitura quanto nos comentários de usuários que postam imagens de capivaras em diversas situações. Veja o exemplo:

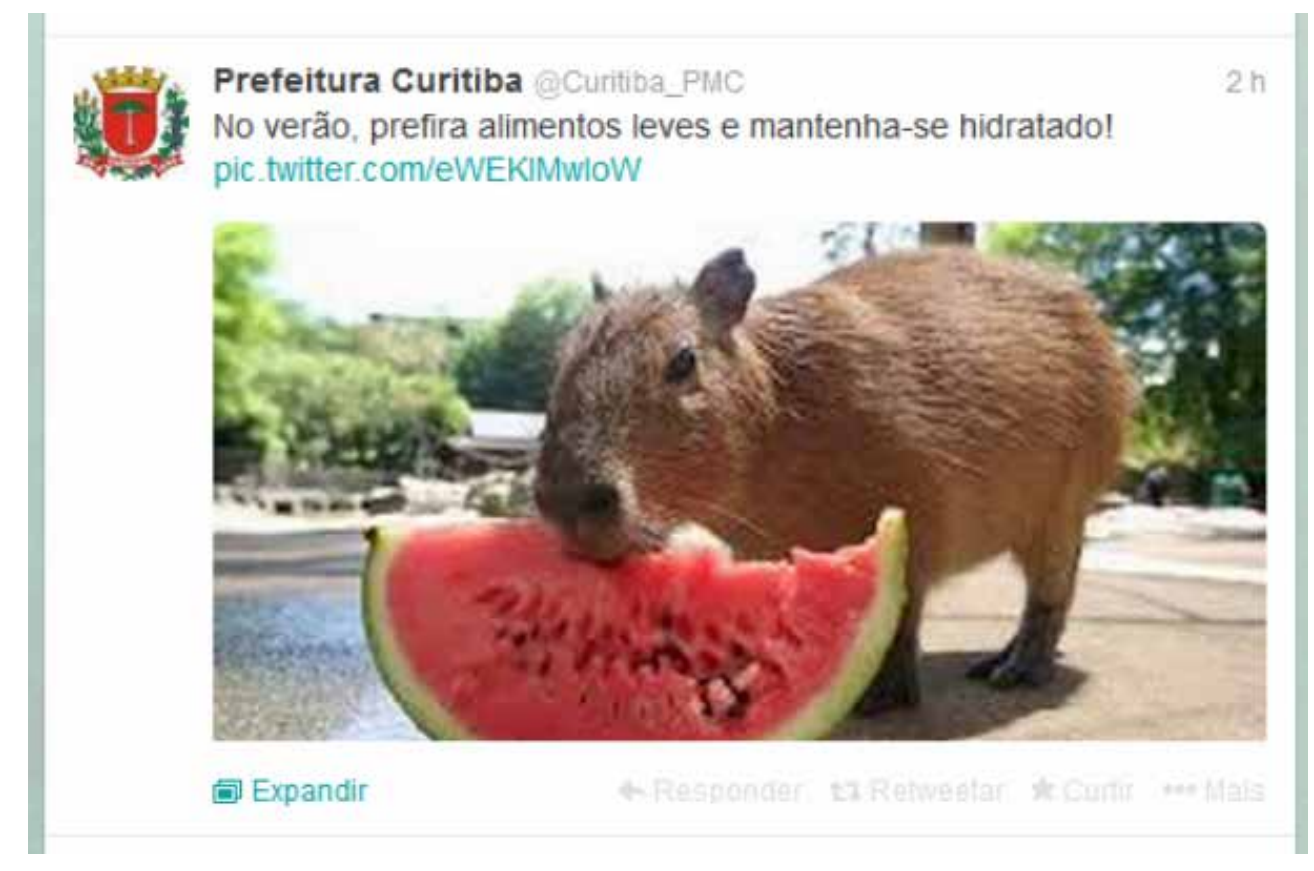

Figura 2: Meme da capivara

A longevidade de um meme depende do quão pertinente e incorporado ao caldo cultural está (RECUERO, 2006). No caso dessa mascote, sua retenção 
pode ser atribuída à relevância que essa figura ganhou ao promover projetos sociais do Instituto Pró-Cidadania de Curitiba.

Conforme aponta Recuero, a utilização de memes está ligada não somente ao foco de elevar o número de interações, como também construir uma reputação, estreitando laços e conquistando novos. Em nível de engajamento, pode-se dizer que, dentre outros produtos criados por essa equipe, a disseminação de conteúdo relevante ganha visibilidade a partir da utilização de memes, por conta do seu caráter descontraído e entretido inscritos na face afetiva da página on-line.

A prefeitura não economiza em memes, sendo essa uma das características que fizeram sua página do Facebook ser a mais acessada em comparação aos perfis das demais capitais brasileiras. Há referências a personagens populares entre o público jovem, como Harry Potter, por exemplo, e até frases famosas no ambiente on-line, personagens de seriados famosos (Game of Thrones, How to Get Away with Murder etc.) ou desenhos e jogos de videogame consagrados (Dragon Ball Z e Super Mario Bros., por exemplo). Seguem exemplos com as respectivas legendas utilizadas na própria fan page:

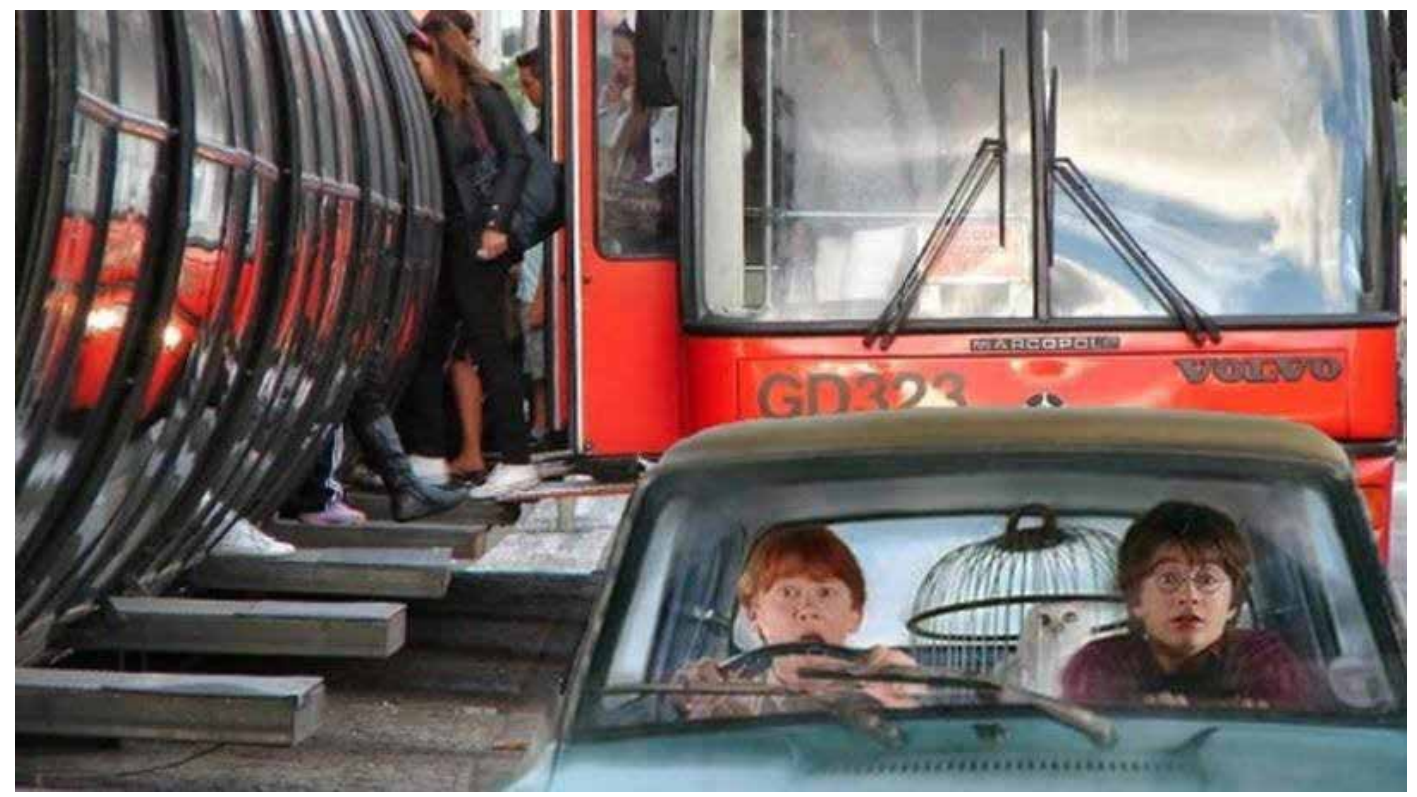

Figura 3: Prefeitura adverte: "Harry, não faça Curitiba de trouxa.

A canaleta é de uso exclusivo do transporte coletivo!" 


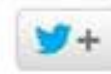

Curitiba inventou a estação tubo em 1991.

Mario já usava o tubo como meio de

transporte em 1985.

pic.twitter.com/xDOainiDn7

$6.25 \mathrm{pm}-11 \mathrm{abr} 14$

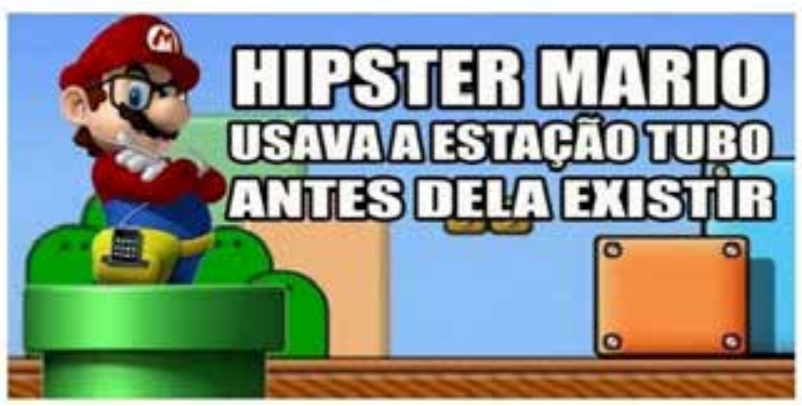

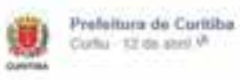

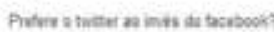

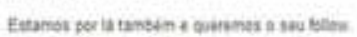

cies converat cementent

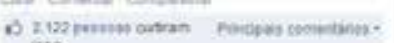

Q 205 entosemamume

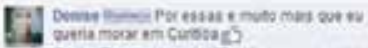
Q is paranata

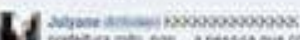

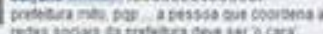

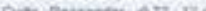

a cenonion

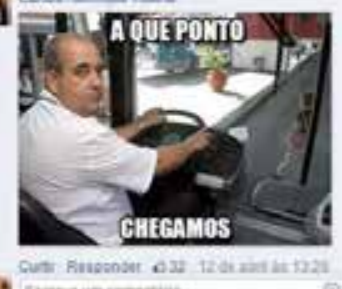

Figura 4: "Prefere o Twitter ao invés do Facebook? Estamos por lá também e queremos o seu follow"

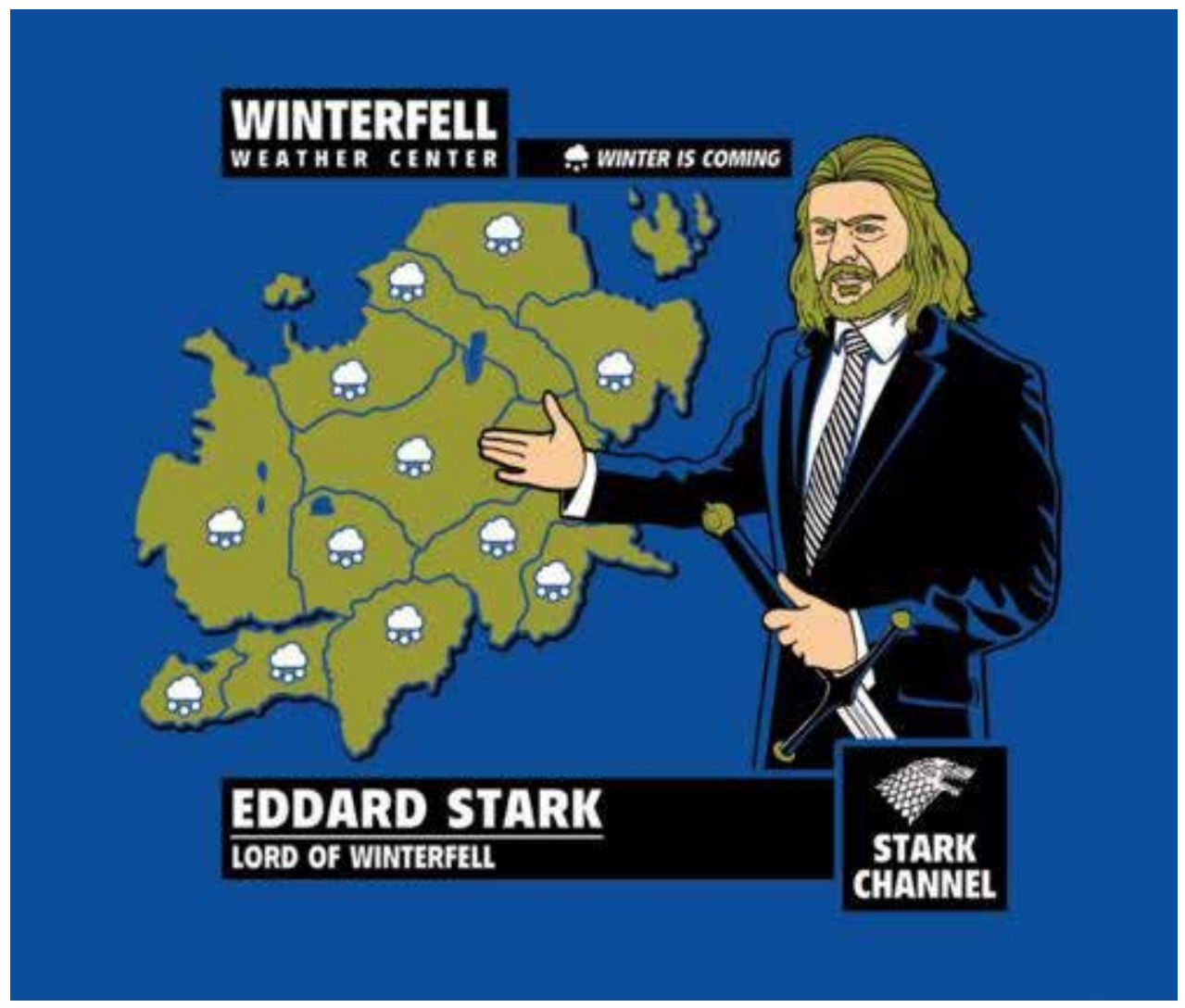

Figura 5: Personagem de Game of Thrones indicando a temperatura da cidade com o jargão do seriado "Winter is coming" 
O trabalho de engajamento realizado pela prefeitura de Curitiba faz com que a instituição ganhe visibilidade e, por meio dessa estratégia, promova acesso ao conteúdo e interesse políticos a partir de uma nova abordagem na democracia digital, entendida, seguindo Gomes (2005), como a extensão das discussões políticas para a internet.

Apesar de algumas críticas sobre o humor na linguagem utilizada ou sobre a alocação de recursos para outras demandas da cidade que não uma área de mídias sociais (CASTRO, 2013), a maior interação de pessoas com a prefeitura de Curitiba gera potencial em termos de cidadania e democracia, uma vez que promove o diálogo com a presença on-line dessa instituição, colocando o relacionamento com os munícipes como objetivo primeiro, além de agilizar sua burocracia interna, uma vez que as pessoas estão exigindo respostas na internet e os setores devem reportar evolução nos processos, conforme ressaltou um dos membros da equipe, Claudio Castro (CASTRO, 2013). O que vai contra a ideia de que a internet demanda resultados imediatos impossíveis de serem obtidos, rotulando-a como inócua (JOSGRILBERG, 2010).

Para reforçar essa ideia, a própria figura da capivara reverte orçamento para projetos sociais da cidade. Ou seja, com a possibilidade do relacionamento on-line, a aproximação de órgãos públicos pode promover a participação (indireta) das pessoas nas questões políticas do município, estado ou federação.

\section{Considerações finais}

As relações entre política e entretenimento se mostram, na página da prefeitura de Curitiba, mediadas pelo vínculo afetivo que se tenta construir com os usuários a partir do uso de referências familiares, sobretudo aquelas advindas da cultura midiática contemporânea. O sentido do afeto, aqui, refere-se sobretudo às possibilidades de ressaltar sentidos para além de uma racionalidade política no debate de questões públicas. 
Os vínculos da política com o entretenimento, ao se pautarem na construção de afetos, indicam uma preocupação - explicitada na entrevista do gestor - em adaptar as decisões do campo político para uma linguagem de fácil assimilação pelos munícipes, na medida de sua familiaridade com as lógicas midiáticas das quais elas são oriundas. Nesse caso, vale ressaltar que não se notou, na pesquisa, qualquer indício de transformações específicas na lógica da política: a visibilidade do campo político, mesmo em suas vinculações afetivas com o entretenimento, continua a ser uma questão estratégica.

Ao mesmo tempo, não é de se descartar uma possível ação reflexiva nas dinâmicas do jogo político. Vale notar, nesse aspecto, que, em comparação com páginas de outras capitais no Facebook, Curitiba está na frente em termos de número de seguidores, e principalmente de interações, superando São Paulo e Rio de Janeiro, com maior número de habitantes do que Curitiba (PINHONI, 2014). Isso talvez possa ser pensado como um eventual ganho de capital político, impossível ainda de ser mensurado. É questionável, além disso, em que medida seria possível falar de um aumento no engajamento político de cidadãs e cidadãos - em que medida esses vínculos afetivos a partir do entretenimento ressaltam a "cultura cívica" do local (DAHLGREN, 2004), em particular por conta de sua dimensão mediada on-line (MARQUES, 2009, 2011; MARTINO; MARQUES, 2011).

É possível questionar, nesse sentido, em que medida a utilização ostensiva do entretenimento não se acomoda, por sua vez, às demandas de uma esfera política na qual os jogos de visibilidade e ocultamento são fundamentais para sua manutenção. Se a linguagem parece estar a cargo de uma equipe voltada para sua construção a partir de uma lógica do entretenimento midiático, por outro lado a tomada de decisões a respeito do conteúdo se mantém, como esperado, sob responsabilidade dos agentes políticos.

O ganho político do uso do entretenimento como uma "estratégia sensível" (SODRÉ, 2006), nesse sentido, ainda espera uma maior mensuração, bem como a possibilidade de tratar os fenômenos contemporâneos de engajamento político a partir de estratégias do entretenimento, com maior profundidade. 


\section{Referências}

AGUIAR, L. Entretenimento: valor-notícia fundamental. Estudos em Jornalismo e Mídia, Florianópolis, v. 5, n. 1, p. 13-23, 2008.

ALEIXO, T. Afeto e política: gênero, processos midiáticos e participação digital das vereadoras da Região Metropolitana de Campinas. 2016. Dissertação (Mestrado em Comunicação) - Faculdade Cásper Líbero, São Paulo, 2016.

- Elementos pessoais e participação política em perfis de vereadores de Itupeva/SP no Facebook. In: SEMINÁRIO MÍDIA, POLÍTICA E ELEIÇÕES, 1., 2014, São Paulo. Anais... São Paulo: PUC-SP, 2014.

BABCOCK, W.; WHITEHOUSE, V. Celebrity as a postmodern phenomenon, ethical crisis for democracy, and media nightmare. Journal of Mass Media Ethics, London, v. 20, n. 2-3, p. 176-191, 2005.

BEETHAM, D. Liberal democracy and the limits of democratization. In: HELD, D. (Ed.). Prospects of democracy: North, South, East, West. Stanford: Stanford University, 1993. p. 55-73.

BRAGA, J. L. Dispositivos interacionais. In: ENCONTRO DA COMPÓS - Grupo de Trabalho Epistemologia da Comunicação, 20., 2011, Porto Alegre. Anais... Belo Horizonte: Compós, 2011.

BRANTS, K.; NEIJENS, P. The infotainment of politics. Political Communication, London, v. 15, n. 2, p. 149-164, 1998. 
BRASIL. Presidência da República. Secretaria de Comunicação Social. Pesquisa brasileira de mídia 2015: hábitos de consumo de mídia pela população brasileira. Brasília, DF: Secom, 2014.

BUCY, E. P.; GREGSON, K. S. Media participation: a legitimizing mechanism of mass democracy. New Media \& Society, London, v. 3, n. 3, p. 357-380, 2001.

CARLSON, J. G.; HATFIELD, E. Psychology of emotion. Fort Worth: Holt, Rinehart and Winston, 1991.

CASTRO, F. Prefeitura brinca com capivaras e nome de Curitiba nas redes sociais. Portal G1, Curitiba, 13 nov. 2013. Disponível em: <http://g1.globo.com/pr/ parana/noticia/2013/11/prefeitura-brinca-com-capivaras-e-nome-de-curitibanas-redes-sociais.html>. Acesso em: 8 jun. 2015.

COUTINHO, C. N. Contra a corrente: ensaios sobre democracia e socialismo. São Paulo: Cortez, 2000.

COUTINHO, I. Dramaturgia do telejornalismo: a narrativa da informação em rede e nas emissoras de televisão de Juiz de Fora, MG. Rio de Janeiro: Mauad X, 2012.

DAHLGREN, P. Reconfiguring civic culture in the new media Milieu. In: CORNER, J.; PELS, D. Media and the restyling of politics: consumerism, celebrity and cynicism. London: Sage, 2004. p. 151-170.

DAVIS, R. Politics online: blogs, chatrooms and discussion groups in American democracy. Nova York: Routledge, 2005.

DAWKINS, R. O gene egoísta. São Paulo: Companhia das Letras, 2010. 
DEJAVITE, F. A. Infotenimento: informação + entretenimento no jornalismo. São Paulo: Paulinas, 2006.

DYER, R. Only entertainment. Londres: Routledge, 1997.

FRIDJA, N. H.; KUIPERS, P.; TER SCHURE, E. Relations among emotion, appraisal, and emotional action readiness. Journal of Personality and Social Psychology, Washington, DC, v. 57, n. 2, ago. 1989, p. 212-228.

FUNG, T. K. F; NAMKOONG, K.; SCHEUFELE, D. A. The politics of emotion: news media attention, emotional responses, and participations during the $2004 \mathrm{U}$. S. presidential election. Mass Communication and Society, London, v. 15, n. 1, p. $25-45,2012$.

GOMES, W. A democracia digital e o problema da participação civil na decisão política. In: ENCONTRO DA COMPÓS - Grupo de Trabalho Comunicação e Política, 14., 2005, Niterói. Anais... Belo Horizonte: Compós, 2005.

- Participação política online: questões e hipóteses de trabalho. In: GOMES, W.; MAIA, R. C. M.; MARQUES, F. P. J. A. (Org.). Internet e participação política no Brasil. Porto Alegre: Sulina, 2011. p. 19-46.

- Transformações da política na era da comunicação de massa. São Paulo: Paulus, 2004.

GONZÁLEZ-BAILÓN, S.; BANCHS, R. E. ; KALTENBRUNNER, A. Emotions, public opinion, and U.S. presidential approval rates: a 5-year analysis of online political discussions. Human Communication Research, Hoboken, v. 38, n. 2, p. 121-143, 2012. 
GROHMANN, R. A comunicação eletrônica é epistemóloga: entrevista com Muniz Sodré. Revista Parágrafo, São Paulo, v. 1, n. 3, p. 121-128, jan./jun. 2015.

HABERMAS, J. A inclusão do outro: estudos de teoria política. São Paulo: Loyola, 2004.

. Direito e democracia: entre facticidade e validade. Rio de Janeiro: Tempo Brasileiro, 1997.

HYDE-CLARKE, N. Facebook and public debate: an informal learning tool for the youth. Journal of African Media Studies, Bristol, v. 5, n. 2, p. 131-148, 2013.

JOSGRILBERG, F. B. A opção radical pela comunicação na cidade. In: SILVEIRA, S. A. (Org.). Cidadania e redes digitais: citizenship and digital networks. São Paulo: Comitê Gestor da Internet no Brasil: Maracá - Educação e Tecnologias, 2010. p. $155-183$.

MARQUES, A. C. S. Aspectos teórico-metodológicos do processo comunicativo de deliberação online. Revista Brasileira de Ciência Política, Brasília, DF, n. 6, p. $19-40,2011$.

- La conversation civique sur internet: contributions au processus délibératif. Estudos em Comunicação, Curitiba, n. 5, p. 21-52, maio 2009.

MARTINO, L. M. S. Teoria das mídias digitais. Petrópolis: Vozes, 2014. - Três hipóteses sobre as relações entre mídia, entretenimento e política. Revista Brasileira de Ciência Política, Brasília, n. 6, p. 137-150, jul./dez. 2011. 
MARTINO, L. M. S.; MARQUES, A. C. S. Promises and limits of discourse ethics in communicative interactions. Estudos em Comunicação, Curitiba, n. 10, p. 1-21, dez. 2011.

MEYER, T. Media democracy. London: Polity, 2002.

MUIR, K. Media darlings and falling stars: celebrity and the reporting of political leaders. Westminster Papers in Communication and Culture, London, v. 2, n. 2, p. 54-71, 2005.

MUTZ, D. C.; YOUNG, L. Communication and public opinion: plus ça change? Public Opinion Quarterly, Oxford, v. 75, n. 5, p. 1018-1044, 2011.

NUNES, M. R. F. A memória na mídia. São Paulo: Annablume, 2004.

PINHONI, M. Curitiba é hoje cidade mais engraçada do Brasil. Portal Exame, São Paulo, 24 abr. 2014. Disponível em: <http://exame.abril.com.br/brasil/noticias/curitiba-ehoje-cidade-mais-engracada-do-brasil-veja-razao>. Acesso em: 8 jun. 2015.

RAWLS, J. O direito dos povos. São Paulo: Martins Fontes, 2004.

RECUERO, R. C. Memes e dinâmicas sociais em weblogs: informação, capital social e interação em redes sociais na internet. Intexto, Porto Alegre, v. 2, n. 15, p. 1-16, jul./dez. 2006.

REES, L. Selling politics. London: BBC Books, 1992.

SANTOS, F. Prefeitura de Curitiba usa humor no Facebook e ganha fãs. Portal Terra, São Paulo, 16 abr. 2014. Disponível em: <http://noticias.terra.com.br/ 
brasil/cidades/prefeitura-de-curitiba-usa-humor-no-facebook-e-ganha-fas, 1042 b5ae60a65410VgnVCM3000009af154dORCRD.html>. Acesso em: 8 Jun. 2015.

SHIFMAN, L. Memes in digital culture. Cambridge, MA: MIT, 2013.

SIBILIA, P. O show do eu: a intimidade como espetáculo. Rio de Janeiro: Nova Fronteira, 2008.

SODRÉ, M. As estratégias sensíveis: afeto, mídia e política. Petrópolis: Vozes, 2006. . O Brasil simulado e o real: ensaios sobre o quotidiano nacional. Rio de Janeiro: Rio Fundo, 1991.

STREET, J. Mass media, politics and democracy. New York: Palgrave, 2001. . Politics and popular culture. London: Polity, 1997. . Politics lost, politics transformed, politics colonised? Theories of the impact of mass media. Political Studies Review, Hoboken, v. 3, n. 1, p. 17-33, 2005.

VAN ZOONEN, L. Entertaining the citizen: when politics and popular culture converge. Lanham: Rowman \& Littlefield, 2005.

. Imagining the fan democracy. European Journal of Communication, Thousand Oaks, v. 19, n. 1, p. 39-52, 2004.

WASHBOURNE, N. Mediating politics: newspapers, radio, television and the Internet. New York: Open University, 2010.

WEBER, M. H. Comunicação e espetáculos da política. Porto Alegre: UFRGS, 2000. 
Imagem pública. In: RUBIM, A. A. C. (Org.). Comunicação e política: conceitos e abordagens. Salvador: Edufba, 2004. p. 259-308.

WILHELM, A. G. Democracy in the digital age: challenges to political life in cyberspace. New York: Routledge, 2000.

WOJDYNSKI, B. W.; RIFFE, D. What kind of media, and when? Public opinion about press coverage of politicians' private lives. Journal of Mass Media Ethics, London, v. 26, n. 3, p. 206-223, 2011.

YOUNG, L.; SOROKA, S. Affective news: the automated coding of sentiment in political texts. Political Communication, London, v. 29, p. 205-231, 2012.

submetido em: 27 maio 2016 | aprovado em: 10 jul. 2016 